\title{
8 Anos de Informática na Educação nas Escolas Públicas Municipais de Ipatinga/MG: avanços e retrocessos
}

\author{
Márcia de Freitas Vieira ${ }^{1}$ \\ ${ }^{1}$ Faculdade Pitágoras de Ipatinga \\ Rua Jequitibá, 401, Horto - 35.160-306 - Ipatinga - MG - Brasil \\ marcia.ipatinga@gmail.com
}

\begin{abstract}
From the context of the Brazilian scenario insertion of computers in public schools, this paper presents the partial results of a survey on the use of computer labs in schools of Ipatinga/MG, after eight years of implementation of the Inclusion Project digital proposed by the Municipal Government. The results of this investigation reveal weaknesses and problems arising from change management of the municipality for the continuity of work in educational computing and the need to adopt a new policy in the city to rescue the use of digital technologies in educational settings, where conditions for teachers to integrate activities of educational software in the curriculum content of their disciplines.
\end{abstract}

Resumo. A partir da contextualização do cenário brasileiro de inserção de computadores nas escolas públicas do país, este artigo apresenta os resultados parciais de uma pesquisa sobre a utilização dos laboratórios de informática nas escolas municipais de Ipatinga/ $\mathrm{MG}^{1}$, após oito anos de implantação do Projeto de Inclusão Digital proposto pelo Governo Municipal. Os resultados desta investigação apontam problemas e fragilidades decorrentes das mudanças de gestão do município para a continuidade dos trabalhos em informática educacional e a necessidade de adoção de uma nova política no município para resgatar a utilização das tecnologias digitais no contexto educacional, dando condições aos professores de integrar as atividades dos softwares educacionais ao conteúdo curricular de suas disciplinas.

\section{Percorrendo políticas públicas de informática na educação no Brasil}

O Brasil, impulsionado pelo desenvolvimento econômico e pelo "boom" tecnológico, em que a sociedade é dominada pelos avanços e inovações tecnológicas, vem respondendo positivamente aos programas internacionais de democratização de acesso aos recursos tecnológicos em diferentes espaços socioculturais.

Com o objetivo de desenvolver políticas nacionais para a sua inserção neste mundo de tecnologias, conexões e de globalização e assegurar uma posição de competitividade econômica no cenário internacional, diversos países no mundo inteiro desenvolveram o programa Sociedade da Informação. O Brasil também

\footnotetext{
1 Ipatinga é uma cidade localizada na Região Metropolitana do vale do aço (RMVA), leste de Minas Gerais, a 217 km de Belo Horizonte, capital do Estado. Foi fundada em 1962 e cobre uma área total de $166,5 \mathrm{Km}^{2}$. Sua população é de 227.338 habitantes [IBGE 2005].
} 
empreendeu esforços nesse sentido. $\mathrm{O}$ esforço para construção de diretrizes para o desenvolvimento de um programa que inserisse a sociedade brasileira na sociedade da informação deu origem à publicação, em 2000, do Livro Verde da Sociedade da Informação. (BORGES, 2008)

Desde a década de 70, quando tiveram início as primeiras investigações sobre o uso do computador na educação no Brasil, a partir de algumas experiências nas Universidades Federal do Rio de Janeiro (UFRJ), Rio Grande do Sul (UFRGS) e UNICAMP (MORAES,1997b), tem havido investimentos por parte das autoridades governamentais na melhoria da educação pública, visando à formação de uma geração capaz de competir no mercado de trabalho e, sobretudo, na sociedade globalizada.

O projeto EDUCOM foi a primeira iniciativa concreta de se levar o computador às escolas públicas, significando o ponto de partida para se consolidar uma política de informática voltada para as questões educacionais. Desde então, várias ações governamentais como a criação do Comitê Assessor de Informática para Educação de $1^{\circ}$ e $2^{\circ}$ Graus (Caie/Seps) e o projeto Formar (1986), o Programa de Ação Imediata em Informática na Educação (1987), o Projeto CIED - Centros de Informática na Educação (1988), o PRONINFE - Programa Nacional de Informática Educativa (1989) e o PROINFO - Programa Nacional de Informática na Educação (1997), vêm definindo uma política de informática na educação pública brasileira (VIEIRA, 2011).

Moraes (1997b) reconhece que apesar das várias dificuldades apresentadas durante todo o desenvolvimento dos projetos de informática na educação, propostos pelo MEC até 1995, a estratégia de implantação adotada mostrou-se adequada, tendo em vista a capacidade de disseminação e multiplicação dos subcentros e laboratórios por parte de alguns estados e municípios brasileiros.

Após um período em que questões políticas e administrativas provocaram um atraso nos cronogramas e nas metas estabelecidas em 1997, o governo federal retoma em 2005 as ações do PROINFO. A informatização das escolas públicas é uma das metas previstas no Plano Nacional de Desenvolvimento da Educação (PDE).

Além da retomada do PROINFO, o Governo Federal tem executado e apoiado outras ações de inserção da informática nas escolas públicas por meio de diversos programas e órgãos (Brasil, 2008), (Brasil, 2009):

* Programa Nacional de Formação Continuada em Tecnologia Educacional.

* e-Proinfo.

* Sistema Escola Técnica Aberta do Brasil.

* Projeto UCA (Um Computador por Aluno).

* Projeto Banda Larga nas escolas.

* Mídias na educação.

* Rede Nacional de Formação de Professores.

* Banco Internacional de Objetos Educacionais.

\section{O PROINDI nas escolas municipais de Ipatinga/MG}

Neste cenário brasileiro, com o objetivo de tornar Ipatinga/MG a primeira cidade digital de porte médio do país, a administração municipal vigente em 2005-2008, elaborou o Programa Ipatinga Digital, englobando uma série de projetos, dentre os quais: a 
instalação de quiosques com acesso livre à internet em toda a cidade, a implantação de laboratórios de informática nas escolas municipais, o desenvolvimento de um sistema para automação da gestão escolar e a instalação de infovias no município (Borges, 2007).

O Projeto Inclusão Digital (PROINDI) consistiu na implantação de laboratórios de informática em todas as escolas da rede, com acesso a um portal educacional para alunos do $3^{\circ}$ e $4^{o}$ ciclos (correspondentes a $5^{\mathrm{a}}$ a $8^{\mathrm{a}}$ série) e a aquisição de mesas pedagógicas $^{2}$ e softwares educativos para alunos da educação infantil, $1^{\circ}$ e $2^{\circ}$ ciclos (pré-escolar a $4^{\mathrm{a}}$ série) e educação especial. Contemplou ainda, um programa de formação para todos os professores da rede municipal e suporte técnico e pedagógico durante dois anos.

Borges (2007) aponta muitas contribuições trazidas para o processo educacional da rede municipal com a instalação dos laboratórios de informática, onde destaca, como mais relevantes:

- maior participação dos alunos na escola, com melhorias na disciplina, na freqüência e no respeito às regras;

- os alunos que têm aula no laboratório de informática demonstram maior interesse pelas atividades escolares e apresentam melhorias no raciocínio lógico e na fixação dos conteúdos trabalhados;

- o trabalho em equipe, propiciado no laboratório, possibilita a socialização do conhecimento e maior interação entre os alunos;

- além de ajudar na aprendizagem, tornando-a mais prazerosa, tem possibilitado aos alunos, na maioria muito carentes, acesso ao computador e à tecnologia;

- diminuiu o trabalho do professor na confecção de matrizes de jogos, quebra cabeça, entre outros;

- têm permitido desenvolver um trabalho complementar com os alunos que possuem maiores dificuldades;

- o trabalho realizado com alunos portadores de deficiência mental e/ou dificuldades especiais (deficientes auditivos e deficientes visuais) nos laboratórios de informática tem propiciado uma melhora gradual de aprendizagem. Para estes alunos as TIC podem representar a abertura de novos espaços de expressão e inserção social.

\section{Procedimentos metodológicos da pesquisa}

Diante do Projeto de Inclusão Digital implantado nas escolas municipais de Ipatinga e da pesquisa realizada por Borges (2007) sobre o processo de implantação do mesmo, fez-se pertinente nova pesquisa para avaliação da situação atual de utilização dos laboratórios de informática nas escolas públicas municipais de Ipatinga.

\footnotetext{
${ }^{2}$ Mesas pedagógicas são integradas por módulos eletrônicos, softwares educacionais e materiais concretos que proporcionam um ambiente colaborativo de aprendizagem. Permitem o trabalho conjunto de até seis crianças, favorecendo a socialização e o desenvolvimento de atividades em grupo.
} 
Com o objetivo de averiguar quais os movimentos desencadeados nesse processo, iniciou-se uma pesquisa qualitativa e descritiva, em formato de estudo de caso, enfocando a realidade de Ipatinga/MG. A pesquisa encontra-se na etapa de identificação das situações de utilização dos laboratórios de Informática no município.

Como processos metodológicos de coleta de dados, foram realizadas observações in loco e análise documental dos registros de implementação do PROINDI. Além disso, foram realizadas entrevistas semi-estruturadas com gestores escolares e questionários aplicados a coordenadores pedagógicos, professores regentes e a alunos das 37 escolas da rede municipal.

A pesquisa procurou identificar a situação dos laboratórios de informática e como tem sido a utilização dos mesmos, após oito anos de implantação do Projeto. Os questionários aplicados englobavam questões como: quantidade de computadores nos laboratórios, quais os softwares instalados, como acontece o planejamento das aulas nos laboratórios de informática, capacitação dos professores e mediadores, frequência com que são utilizados os laboratórios, dentre outras.

\section{Resultados encontrados}

É triste constatar no contexto pesquisado, uma realidade deplorável, de completo descaso das autoridades municipais, a descontinuidade de um projeto que já produzia frutos, no sentido da democratização de acesso aos recursos tecnológicos e processo educacional.

Do ano de 2005 (ano de início do Projeto) até o ano vigente, foi verificado um retrocesso na utilização dessas novas tecnologias. Na realidade, constatou-se que não há mais um trabalho de informática educacional sendo realizado. Foram encontrados cerca de $40 \%$ dos laboratórios de portas fechadas, onde não é possível o acesso frequente por alunos e professores, devido à falta de recursos. Muitos desses laboratórios necessitam de manutenção e mais investimento. $94 \%$ deles estão conectados à internet e possuem softwares educacionais instalados, porém, pouco utilizados. Em duas escolas, os computadores foram recolhidos e os laboratórios foram transformados em sala de aula.

Conforme os entrevistados, após a mudança da Administração Municipal, foram retirados os professores monitores dos laboratórios e colocados estagiários técnicos de informática, o que causou grande desmotivação nos professores para a utilização dos recursos tecnológicos nas suas aulas.

Os professores monitores ajudavam muito na elaboração e acompanhamento das atividades realizadas nos laboratórios, pois tinham conhecimento pedagógico e da tecnologia. Os estagiários de informática não detinham esse conhecimento. Posteriormente, até mesmo os estagiários foram retirados das escolas, o que inviabilizou ainda mais o trabalho.

De uma maneira geral, os laboratórios de informática do contexto pesquisado se encontram atualmente na seguinte situação:

$\checkmark$ Computadores danificados ou falta de equipamentos;

$\checkmark$ Alguns computadores funcionando, mas não sendo utilizados;

$\checkmark$ Quando solicitada a manutenção, há enorme demora no atendimento ou quase não se tem retorno; 
$\checkmark$ Falta de assistência técnica e de suprimentos para reposição de peças danificadas;

$\checkmark$ Laboratórios se tornaram depósitos de outros materiais;

$\checkmark$ Não existe mais um profissional específico para o acompanhamento das atividades junto ao professor regente;

$\checkmark$ Não tem havido investimento da Administração Municipal para continuidade do programa.

Os poucos professores que ainda utilizam os laboratórios, o fazem como desejam, sem o acompanhamento pedagógico e muitas das vezes, é mais um momento de descontração para os alunos. Alguns professores, que já viam a tecnologia como um recurso habitual nas suas estratégias de ensino e no cotidiano, fazem o que podem, dependendo da infra-estrutura que encontram na escola.

\section{Percalços comuns na implantação dos programas governamentais}

A realidade constatada no município de Ipatinga/MG não difere do contexto nas demais regiões no Brasil. Pesquisadores ${ }^{3}$ da área têm apresentado relatos freqüentes sobre a inserção da informática nas escolas e as dificuldades que as escolas enfrentam para o uso efetivo da tecnologia no processo educacional.

Características peculiares às tecnologias da informação, em conjunto com a situação da escola pública brasileira, têm contribuído para a escassez de experiências com um mínimo de sucesso. As bem sucedidas estão em Estados que desenvolveram políticas específicas para o setor, porém o processo de implementação dos programas e projetos de Informática na Educação, no âmbito da rede pública de ensino, vem sendo marcado pela descontinuidade, na medida em que as ações e os investimentos do Governo se subordinam a interesses econômicos e políticos (Borges, 2007).

A implantação de laboratórios de informática em todas as escolas públicas do país, prometida pelo governo federal, esbarra no despreparo dos professores para usar o computador e na falta de manutenção dos equipamentos e das instalações, responsabilidade de Estados e Municípios.

Observa-se na maioria das escolas uma subutilização de equipamentos porque os professores não sabem usá-los como ferramentas de ensino. A falta de qualificação dos professores coloca em risco o investimento feito. Os cursos para capacitação dos professores existem, mas não chegam adequadamente ao público interessado. $\mathrm{O}$ Proinfo Integrado, curso com carga horária de 140 horas de introdução à educação digital e de preparação do professor para utilizar a tecnologia como ferramenta pedagógica, é um exemplo.

A segunda causa da baixa utilização é a falta de manutenção das máquinas e instalações ou de adaptação dos imóveis para abrigar os equipamentos, o que é responsabilidade dos Estados e Municípios.

Uma das maiores evidências da falta de coordenação e comunicação entre os órgãos das diversas instâncias governamentais para universalização dos computadores nas escolas é a instalação de cabos para internet em banda larga em escolas sem

\footnotetext{
${ }^{3}$ Almeida ( 2005), Borges (2007), Cysneiros (2000), Moraes (2006), Tono (2008).
} 
computador. A banda larga gratuita nas escolas públicas urbanas foi negociada, em 2008, pelo governo federal com as concessionárias de telefonia fixa. Como a instalação da banda larga e a informatização são projetos distintos, nem sempre a internet chega onde há computador.

De acordo com Vieira (2011), os programas governamentais "são importantes, mas devem respeitar as características de cada escola. O uso do computador deve ser definido sobre o tipo de problema que a escola tem, a partir de um diagnóstico da escola, de seus problemas sociais, do seu projeto político pedagógico, respondendo às questões: Qual a perspectiva do uso ou não do computador na escola? Que projeto político pedagógico a escola tem para alfabetizar, que demanda o uso do computador? A informática deve ser utilizada à medida que o processo de alfabetização demanda a necessidade."

\section{Reflexões sobre a evolução no uso da Informática na Educação}

O papel da escola muda em função do momento histórico, refletindo, em sua estrutura, os acontecimentos sociais e econômicos de uma determinada época. Na passagem da sociedade pré-industrial à industrial e da sociedade industrial à pós-industrial, ocorreram mudanças econômicas, sociais e políticas. Essas transformações impõem à escola mudanças em sua estrutura, exercendo papel fundamental no momento de transição.

O século XXI, era da informação e comunicação, é marcado pela supervalorização do conhecimento e do uso das tecnologias digitais. O conhecimento passa a ter um valor significativo na criação de oportunidades, o que provoca, na educação, uma reflexão sobre suas práticas e sua própria função.

Schneider ET AL (2011) apontam que

Relacionando as políticas públicas propostas pelo Ministério da Educação e pelo Ministério da Ciência de Tecnologia, podemos construir uma imagem representativa do cenário educacional brasileiro como uma moeda de dupla face: por um lado, inclusiva e, por outro, tecnológica. Inclusão e tecnologia são temáticas que se entrecruzam quando abordamos questões relacionadas à escola atual.

As tecnologias digitais vêm propiciando novas formas de acesso a informações, novos modos de pensar e novas dinâmicas no processo de construção do conhecimento. Pesquisas $^{4}$ apontam que $o$ uso dessas tecnologias na educação favorece $o$ desenvolvimento da autonomia, da criatividade, da cooperação e da ativação do processo cognitivo.

É na escola que o homem se apropria de todo o conhecimento disponível na sociedade e construído ao longo da história da humanidade. Portanto, não pode omitir, por muito tempo, componentes culturais da vida cotidiana. Quanto mais as tecnologias de informação e comunicação se tornam presentes na cultura cotidiana, mais elas tendem a ser incorporadas aos processos escolares.

\footnotetext{
${ }^{4} \mathrm{Na}$ Universidade Federal do Rio Grande do Sul (UFRGS), na Universidade Estadual de Campinas (UNICAMP) e na Pontifícia Universidade Católica de São Paulo (PUC/SP), dentre outras.
} 
A Informática no ensino de qualquer disciplina, não pode estar dissociada de uma visão crítica acerca da tecnologia, como forma histórica de desenvolvimento da sociedade e construção do próprio homem, se estiver, de fato, preocupada e comprometida com a formação do cidadão.

Se o objetivo, ao inserir o computador na educação, é favorecer a construção do conhecimento, a mera apresentação do computador e das operações instrumentais para o seu uso é insuficiente e não aumenta, necessariamente, a autonomia nem estimula a criatividade. $\mathrm{O}$ ideal é que o aluno possa interagir com ambientes informatizados que acrescentem valor aos meios tradicionais utilizados no processo educativo. Para tanto, é de suma importância a qualidade dos softwares adotados pelas escolas e sua adequação à proposta político-pedagógica das mesmas.

Alguns fatores como periodicidade de trabalho nos laboratórios de informática, planejamento das atividades, sincronia entre as atividades realizadas no laboratório e o trabalho em sala de aula e a vinculação ao projeto político-pedagógico são fundamentais para o sucesso do uso dessa tecnologia no processo pedagógico (Borges, 2007).

Em síntese, a sociedade informacional e os processos de construção de conhecimento demandam, além de novos ambientes de aprendizagem, novas metodologias e novas práticas fundamentadas que enfatize a aprendizagem e não o ensino, a construção do conhecimento e não a instrução.

Dessa forma, pode-se pensar em uma transformação no processo de ensinoaprendizagem, não apenas pela utilização da informática na educação, mas também pela sua integração à prática pedagógica, o que exige um processo de formação contínua do professor e de mudança de paradigma da escola. Não se busca uma melhor transmissão de conteúdos, nem a informatização do processo ensino-aprendizagem, mas uma transformação educacional que favoreça a formação de cidadãos mais críticos, com autonomia para construir o próprio conhecimento.

\section{Conclusão}

É de fundamental importância para a educação brasileira, a elaboração e implantação de projetos pelas instâncias governamentais que popularizem as tecnologias digitais, socializando os mecanismos de inserção do homem no contexto atual, para que a inovação tecnológica não seja mais um mecanismo de segregação social.

A decisão política de implantação da informática no processo educacional seja oriunda de uma política educacional, fatores de marketing ou democratização de acesso aos recursos informacionais, é um marco importante para promoção de uma cultura tecnológica entre alunos, educadores e toda a comunidade escolar (Vieira, 2011).

Nesta análise, percebe-se que, assim como no contexto brasileiro, as escolas da rede municipal de Ipatinga, encontram ainda, dificuldades com relação ao tipo de uso, formação de professores, má condução de implantação de programas governamentais, muita propaganda política equipando escola sem formação de professores e gestores.

Considerando que estar inserido em um mundo digital constitui um direito do cidadão, como forma de inclusão social, não se vê tal direito ser efetivamente cumprido por parte dos poderes públicos da Prefeitura Municipal de Ipatinga. Infelizmente, um 
projeto que poderia estar beneficiando a formação de milhares de crianças, propiciando a inclusão digital e apropriação do conhecimento de uma forma mais construcionista, está estagnado.

É urgente a reformulação do projeto pelas autoridades municipais e gestores escolares e que sejam tomadas as iniciativas necessárias para resgatar a utilização das tecnologias digitais no contexto educacional, dando condições aos professores de integrar as atividades dos softwares educacionais ao conteúdo curricular de suas disciplinas.

Não se pode deixar de considerar também que tanto a educação quanto a tecnologia, compreendem processos culturais estritamente ligados ao processo produtivo e aos interesses políticos. É preciso redirecionar incrementos tecnológicos para o atendimento dos interesses e necessidades dos setores dominados da sociedade, e que constituem a maioria da população brasileira.

\section{Referências bibliográficas}

Borges, Márcia de Freitas Vieira. (2007) "Inserção da informática no ambiente escolar: inclusão digital e laboratórios de informática numa rede municipal de ensino". Belo Horizonte, Cefet-MG (Dissertação de mestrado).

Borges, Márcia de Freitas Vieira. (2008) "Diálogos com o futuro e respostas ao presente: políticas públicas para utilização da informática no contexto escolar". Anais XIX Simpósio Brasileiro de Informática na Educação (SBIE 2008).

Brasil (2008). "Inclusão Digital" http://www.inclusaodigital.gov.br/inclusao/ Governo Federal.

Brasil (2009). "Portal do Professor" http://portal.mec.gov.br/ Governo Federal.

Moraes, Maria Cândida (1997a). "O paradigma educacional emergente”, Campinas: Papirus.

Moraes, Maria Cândida (1997b). "Informática Educativa no Brasil: Uma História Vivida, Algumas Lições Aprendidas", São Paulo.

Schneider, Fernanda Chagas; Santarosa, Lucila Maria Costi; Conforto, Débora (2011). "Cidade Um Computador por Aluno - UCA Total: A identificação de situações inclusivas na totalidade". Anais do XXII SBIE - XVII WIE.

Vieira, Márcia de Freitas (2011). "25 anos de informática na educação brasileira”. Anais do XXII SBIE - XVII WIE. 